\title{
IL-2 Induces Vasopressin Release from the Hypothalamus and the Amygdala: Role of Nitric Oxide-mediated Signaling
}

\author{
Jacob Raber and Floyd E. Bloom \\ Department of Neuropharmacology, The Scripps Research Institute, La Jolla, California 92037
}

The neuropeptide arginine vasopressin (AVP) can replace the cytokine interleukin 2 (IL-2) as a T-cell mitogen for the induction of interferon $\gamma$ (IFN $\gamma$ ) expression in splenic cultures. IL-2-like and IL-2 receptor immunoreactivity have been reported in different brain regions, under normal and pathophysiological conditions. Regulatory functions for IL-2 in the CNS have been suggested. In addition to the spleen, AVP might also mediate some IL-2 effects centrally. In the present study, we evaluated the effect of IL-2 on the in vitro release of AVP from the hypothalamus and amygdala. In addition, we used these release systems to study the possible involvement of NO-mediated signaling in AVP release, based on the reported detection of nitric oxide synthase (NOS) in the hypothalamus and amygdala. IL-2 rapidly stimulates AVP release in both regions, in a calcium- and dose-dependent manner. In addition, nitroprusside also induces AVP release. Norepinephrine also induces AVP release from both the hypothalamus, as well as the amygdala. The norepinephrineinduced AVP release is antagonized by phentolamine, but not by propanolol, suggesting an $\alpha$-adrenergic receptor-mediated AVP response in both brain regions. The IL-2- and acetylcholine-induced AVP release is antagonized by $\mathrm{N}$ methyl-L-arginine, indicating a role for NO in this AVP release. $\mathbf{N}$-methyl-L-arginine does not affect the norepinephrine-induced AVP release. A stimulatory effect of IL-2 on hypothalamic CRF release and plasma ACTH has already been reported. Our results suggest that in addition to CRF, AVP may also mediate the IL-2 stimulation of ACTH secretion. These data further suggest that in addition to the hypothalamus, the amygdala may also play a role in the bidirectional communication between neuroendocrine and immune systems. Understanding the mode of interaction between IL-2 with AVP could clarify the pathophysiologic or toxic effects of high brain levels of IL-2.

[Key words: vasopressin, hypothalamus, amygdala, rat, acetylcholine, norepinephrine, interleukin-2, nitric oxide]

Accumulating evidence suggests that cytokines play a key role in the bidirectional communication network linking the neuroendocrine and immune systems. The cytokines interleukin-1

Received Dec. 9, 1993; revised Feb. 28, 1994; accepted Apr. 13, 1994.

We thank Drs. E. Merlo Pich, G. F. Koob, and P. Magistretti for helpful criticisms. This work was supported by NIMH AIDS Center Grant MH 47680 and the Schumacher-Kramer Foundation. This is manuscript 8363-NP of The Scripps Research Institute.

Correspondence should be addressed to Jacob Raber, Ph.D., Department of Neurophamacology, CVN-11, The Scripps Research Institute, 10666 North Torrey Pines Road, La Jolla, CA 92037.

Copyright (C) 1994 Society for Neuroscience $0270-6474 / 94 / 146187-09 \$ 05.00 / 0$
(IL-1) and IL-2 appear to be essential for the immune response (Claman, 1987). IL-1 $\beta$ has been shown to stimulate the hypothalamo-pituitary-adrenal (HPA) axis, and its stimulation of adrenocorticotropin (ACTH) release has been ascribed both to an increased release of corticotropin-releasing factor (CRF) (Berkenbosch et al., 1987, 1989; Sapolsky et al., 1987; Saphier and Ovadia, 1990; Spinedi et al., 1992) and more recently to an increased release of arginine vasopressin (AVP) (Watanobe and Takebe, 1993; Raber et al., 1994).

IL-2 is mainly synthesized by antigen- or mitogen-activated $T$-lymphocytes and enhances their proliferation after antigenic stimulation; IL-2 is also involved in controlling B-cell proliferation and their differentiation into antibody-secreting cells, and induces growth and activation of antigen-independent natural killer and lymphokine-activated killer cells (Nistico and De Sarro, 1991). Endogenous AVP in the CNS has been proposed to be involved in primary antibody responses (Croiset et al., 1990), and AVP can replace the IL-2 requirement for T-cell mitogen induction of interferon $\gamma$ in mouse spleen cell cultures (Johnson and Torres, 1985).

IL-2-like and IL-2 receptor immunoreactivity has been reported in different brain regions, under normal and pathophysiological conditions (Nieto-Sampredo and Chandy, 1987; Luber-Narod and Rogers, 1988; Lapchak and Araujo, 1993), with the highest densities in the median eminence-arcuate nucleus complex of rats (Araujo et al., 1989; Lapchak et al., 1991) and mice (Villemain et al., 1990). IL-2 disruption and penetration of the blood-brain barrier has been reported (Ellison et al., 1987; Saris et al., 1988), and the IL-2 in the CNS could originate from the brain or the periphery. In addition, it is not yet clear whether IL-2 is released from neurons, astrocytes, or microglia. The release of IL-2 from brain slices is not increased in the presence of high potassium, which suggests that IL- 2 is not released from nerve terminals by voltage-sensitive mechanisms (Araujo et al., 1989).

Elevated IL-2 levels have been detected in the CSF of neuroleptic-free schizophrenic patients (Licinio et al., 1993) and patients undergoing IL-2 immunotherapy (Saris et al., 1988). Regulatory functions for IL-2 in the CNS have been suggested (Benveniste et al., 1987; Sabath et al., 1990; Nistico and De Sarro, 1991; Cohen et al., 1992; Sessa et al., 1992; Shimojo et al., 1993). IL-2 induced an increase in plasma ACTH and cortisol levels (Bindon et al., 1983; Lotze et al., 1985; Atkins et al., 1986; Denicoff et al., 1989). In addition, when IL-2 was microinjected into the third cerebral ventricle of rats, it significantly increased the neuronal discharge frequency in the supraoptic and paraventricular nuclei, which secrete AVP. This effect might explain the considerable water retention observed during IL-2 therapy (Bindoni et al., 1988), which can lead to 
fluid accumulation in the lungs (Rosenberg and Lotze, 1986; Urba et al., 1990). In addition, a single injection of IL-2 significantly increased hypothalamic AVP mRNA in nude mice after $12 \mathrm{hr}$, which remained elevated for $5 \mathrm{~d}$ (Pardy et al., 1993). These effects would be explained if IL- 2 could enhance AVP release.

NO in the brain is considered a neuronal messenger and might be synthesized either presynaptically or postsynaptically, and may serve as a retrograde messenger (for review, see Garthwaite, 1991; Madison, 1993). NO-mediated signaling might be involved in AVP release. NOS protein, NADPH-diaphorase activity, and mRNA have been detected in the supraoptic nucleus (Bredt and Snyder, 1992). Furthermore, in dehydrated animals, which show elevated levels of AVP release (Jones and Pickering, 1969), there is a strong increase in NOS immunoreactivity in all magnocellular neurons in the SON, including the ventral and caudal part (Pow, 1992), which contain mainly AVP neurons (Swaab et al., 1975). In addition, colocalization of NOS and AVP has recently been reported in a subpopulation of AVP magnocellular neurons (Moffett and Paden, 1993). NOS was also detected in the amygdala (Pow, 1992), which could be involved in the reported calcium-dependent AVP release from the amygdala (Raber et al., 1994).

The objective of the present study is to determine whether IL- 2 can affect the release of AVP from either the hypothalamus or amygdala, using in vitro paradigms of AVP release, and whether NO could regulate the release of AVP by IL-2 or neurotransmitters, such as acetylcholine and norepinephrine.

\section{Materials and Methods}

Animals. Male Sprague-Dawley rats (Charles River), weighing 200-250 $\mathrm{gm}$, were used in all experiments. The rats were kept two per cage and housed under conditions of constant temperature $\left(18^{\circ} \mathrm{C}\right)$, with lighting during $0600-1800 \mathrm{hr}$, with access to water and food ad libitum.

Dissection of hypothalami and amygdala. Animals were sacrificed by decapitation between 1000 and $1100 \mathrm{hr}$ to avoid circadian variation, and their brains rapidly removed. A brain slicer (San Diego Instruments) was used to obtain a 3-mm-thick coronal slice, including structures -1.8 mm caudal to bregma, according to Paxinos and Watson (1986). The slice was then placed under a low-magnification microscope, and hypothalamic and amygdaloid regions were dissected out. Next the hypothalamus was defined as the region between two vertical cuts, starting from the two lateral hypothalamic sulci, and a horizontal cut through the mammillothalamic tracts and the rhomboid thalamic nucleus. The dissection of the amygdala was obtained by a vertical cut tangential to the external capsule and a diagonal cut along the medial border of the ipsilateral optic tract (Raber et al., 1994). The dissected tissues were placed on a Brinkmann tissue chopper, and $300 \mu \mathrm{m}$ slices were prepared.

Incubation system. Experiments were designed to measure the release of AVP from the sliced tissue. For this purpose, the slices were incubated in balanced Earle's salt solution (GIBCO), supplemented with $0.1 \%$ bovine albumin (Pentex), $60 \mu \mathrm{g} / \mathrm{ml}$ ascorbic acid (Fischer), $0.54 \mathrm{mg} / \mathrm{ml}$ glucose, $20 \mathrm{~mm}$ bacitracin (Sigma), $1 \mu \mathrm{M}$ PMSF (Sigma), and $200 \mathrm{Kal}-$ likrein inhibitor units (KIU)/ml aprotinin (Boehringer-Mannheim) at $37^{\circ} \mathrm{C}$ under an atmosphere of $\mathrm{O}_{2} / \mathrm{CO}_{2}(95 \% / 5 \%)$, for a total of $160 \mathrm{~min}$. The experimental design consisted of serial passage of the minced tissue through different wells [one hypothalamic or two amygdala explant(s) per well], which contained $700 \mu \mathrm{l}$ of medium, at $20 \mathrm{~min}$ intervals, according to the method of Calogero et al. (1989). Overnight, the 48well plates (Costar) were precoated with "SPEA" buffer ( $10 \mathrm{mM} \mathrm{NaH}_{2} \mathrm{PO}_{4}$,

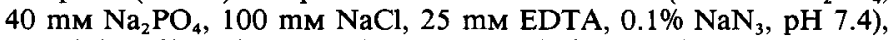
containing $1 \%$ bovine albumin at $4^{\circ} \mathrm{C}$. Media from the incubations were put on dry ice and stored at $-70^{\circ} \mathrm{C}$ until assay for AVP immunoreactivity. The slices were preincubated for $80 \mathrm{~min}$, after which basal AVP release is stabilized (Raber et al., 1994). Between 80 and $100 \mathrm{~min}$, a baseline sample was collected. The slices were exposed to a depolarizing concentration of $\mathrm{KCl}(60 \mathrm{~mm})$ for $20 \mathrm{~min}$ for testing of tissue viability at the end of the experiment. Data from experiments in which there was not a vigorous relcasc (at lcast $50 \%$ ovcr bascline) with $60 \mathrm{mM} \mathrm{KCl}$ were discarded. For studying the effect of IL- 2 on the AVP release from the hypothalamus $(n=7-11)$ and amygdala $(n=5-14)$, tissues were incubated with IL- $2(1,10,50$, or $100 \mathrm{U} / \mathrm{ml})$ between 100 and $120 \mathrm{~min}$.

To investigate if AVP might be released via NO, tissues were incubated with nitroprusside $(100 \mu \mathrm{M})$ between 100 and $120 \mathrm{~min}(n=8$, hypothalamus; $n=20$, amygdala). For studying the calcium dependency of the IL-2-induced AVP release, tissues were incubated with the calcium channel blocker $\mathrm{CoCl}_{2}(10 \mathrm{~mm})$ during basal and IL-2 stimulation (between 100 and $140 \mathrm{~min} ; n=7-28$ ). To investigate the possibility that IL-2 might release AVP via NO, the IL-2 $(100 \mathrm{U} / \mathrm{ml})$-induced AVP release was assessed in the presence of $N^{8}$-methyl-L-arginine (LNMA; $10 \mu \mathrm{M}$ ), a competitive inhibitor of NOS. The inhibitor was present during the basal and IL-2-induced stimulation (between 80 and 120 $\min$ ).

To determine whether acetylcholine or norepinephrine might also induce AVP release via NO, the pharmacologically induced AVP release was assessed in the presence of the NOS inhibitor LNMA $(10 \mu \mathrm{M})$. The inhibitor was present during the basal and acetylcholine ( $1 \mu \mathrm{M} ; n=7-$ 13) or norepinephrine ( $1 \mu \mathrm{M} ; n=9-17)$-induced AVP release. In order to assure that any inhibition of the acetylcholine-induced AVP release by LNMA is specific, the acetylcholine-induced AVP release was also assessed in the presence of $N^{8}$-methyl-D-arginine (DNMA), its inactive analog $(n=7-13)$. To investigate which adrenergic receptor is involved in the norepinephrine-induced release of AVP $(1 \mu \mathrm{M})$, release was studied in the presence of propanolol $(10 \mu \mathrm{M})$ or phentolamine $(10 \mu \mathrm{M})$. The adrenergic antagonists were present during the basal and norepinephrine-induced stimulation (between 80 and $120 \mathrm{~min} ; n=8-21$ ).

$A V P R I A$. The concentration of AVP in the media was measured in polypropylene tubes (Labcraft) by RIA according to the Skowsky method (Skowsky et al., 1974), modified by Weitzman et al. (1978), using a specific rabbit polyclonal antibody (gift from Dr. A. Burlet, Bordeaux, France) and synthetic vasopressin (gift from Dr. P. Plotsky, Atlanta, GA), ${ }^{125}$ I-AVP was obtained from Amersham. Pretitered goat anti-rabbit and normal rabbit sera were from Peninsula Laboratories, Inc. All standards were measured in triplicate and the medium samples were measured in duplicate. The lower detection limit of the assay was $3 \mathrm{pg} /$ tube (100 $\mu$ l sample volume). The intra- and interassay coefficients of variation were $3 \%$ and $10 \%$, respectively.

Substances. Human recombinant IL-2 was from Boehringer-Mannheim. Acetylcholine, norepinephrine, propanolol, phentolamine, cobalt chloride, nitroprusside, $N^{\mathrm{B}}$-methyl-L-arginine, and $N^{\mathrm{B}}$-methyl-D-arginine were from Sigma. All solutions were prepared immediately before incubation.

Statistics. Data, expressed as mean \pm SEM, were analyzed statistically using analysis of variance (ANOVA) followed by a Tukey test when appropriate. A probability value of less than 0.05 was considered significant.

\section{Results}

\section{Effect of $I L-2$ on the basal AVP release from the hypothalamus and the amygdala}

As shown in Figure $1, A$ and $B$, a $20 \mathrm{~min}$ IL-2 incubation stimulated AVP release from both the hypothalamus as well as the amygdala, in a dose-dependent manner with a maximum response at a concentration of $100 \mathrm{U} / \mathrm{ml}$. For the hypothalamus, there was a slight, but statistically significant, increase observed with IL-2 at $1 \mathrm{U} / \mathrm{ml}$. In contrast to the hypothalamus, IL-2 at 1 or $10 \mathrm{U} / \mathrm{ml}$ did not significantly increase AVP release from the amygdala as compared to basal levels. There was an enormous increase in AVP release from both brain regions observed at IL-2 concentration of 50 and $100 \mathrm{U} / \mathrm{ml}$ (for the hypothalamus, $235 \pm 21 \%$ and $389 \pm 32 \%$, and for the amygdala, 257 $\pm 30 \%$ and $440 \pm 40 \%$ over basal, respectively).

\section{Effect of sodium nitroprusside on the basal $A V P$ release}

To determine whether nitric oxide might be involved in AVP release, hypothalamic and amygdala slices were incubated in the presence of $100 \mu \mathrm{M}$ sodium nitroprusside, which generates NO. As shown in Figure 2, $A$ and $B$, sodium nitroprusside 
A

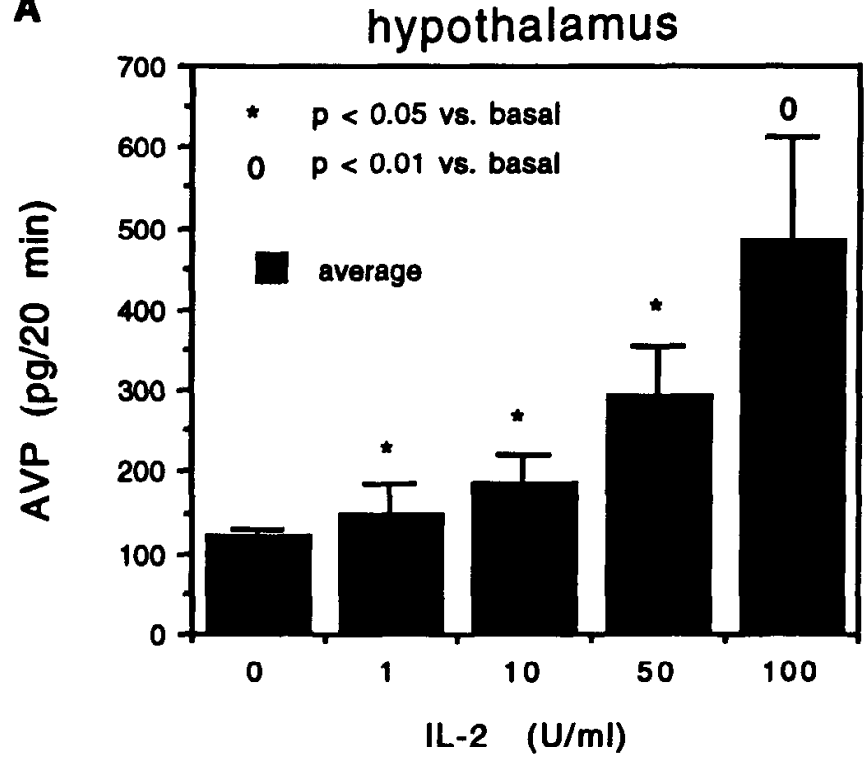

B

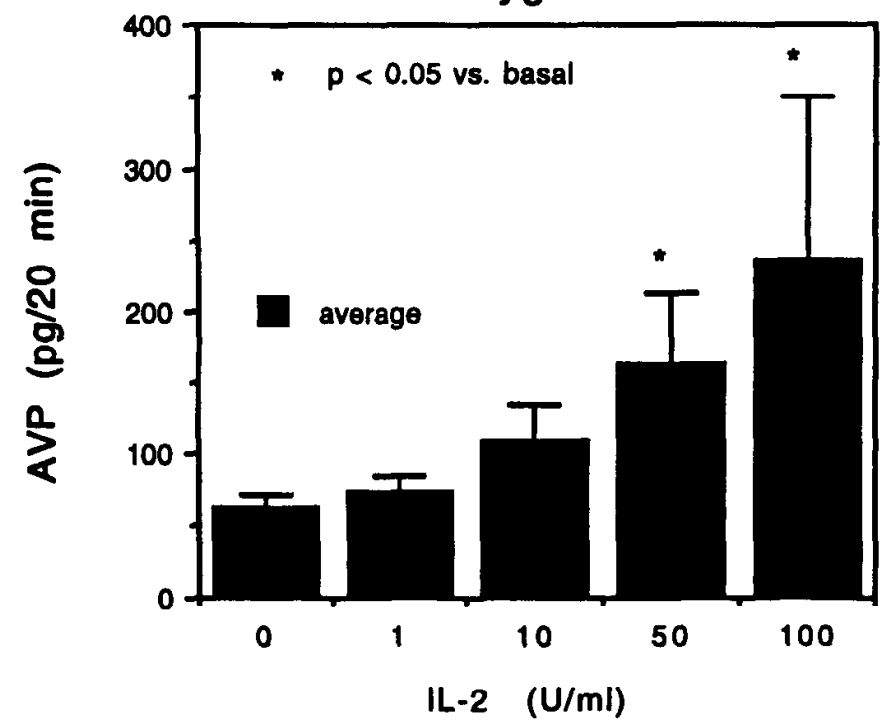

Figure 1. Effect of IL-2 on the basal AVP release from the hypothalamus $(A)$ and amygdala $(B)$. After an 80 min preincubation, a baseline sample was collected for a period of $20 \mathrm{~min}$. The basal values given are the average of the periods collected before the IL-2 stimulation. Incubation was carried out with medium containing increasing concentrations IL $2(1,10,50$, and $100 \mathrm{U} / \mathrm{ml})$ in the subsequent period (between 100 and $120 \mathrm{~min}$ ). In all the subsequent experiments, during the last $20 \mathrm{~min}$, incubation was carried out in $60 \mathrm{mM} \mathrm{KCl}$ to test the viability of the slices (data not shown). All values given are means \pm SEM. $n=$ 7-11 for hypothalamus $(A) ; n=5-14$ for amygdala $(B) .{ }^{*}, p<0.05$ versus basal; $0, p<0.01$ versus basal.

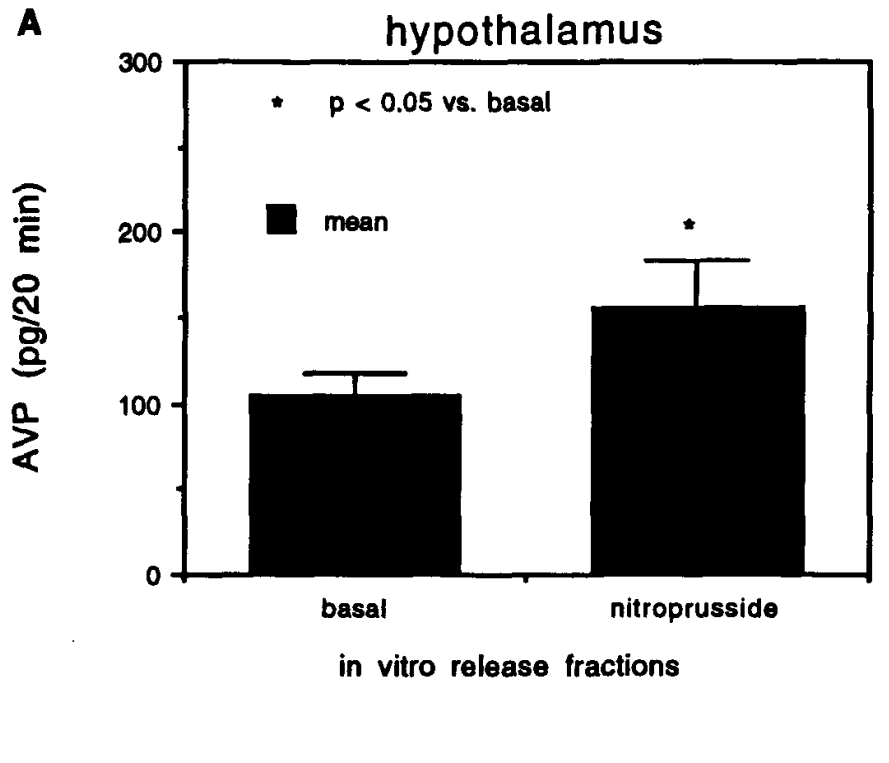

B

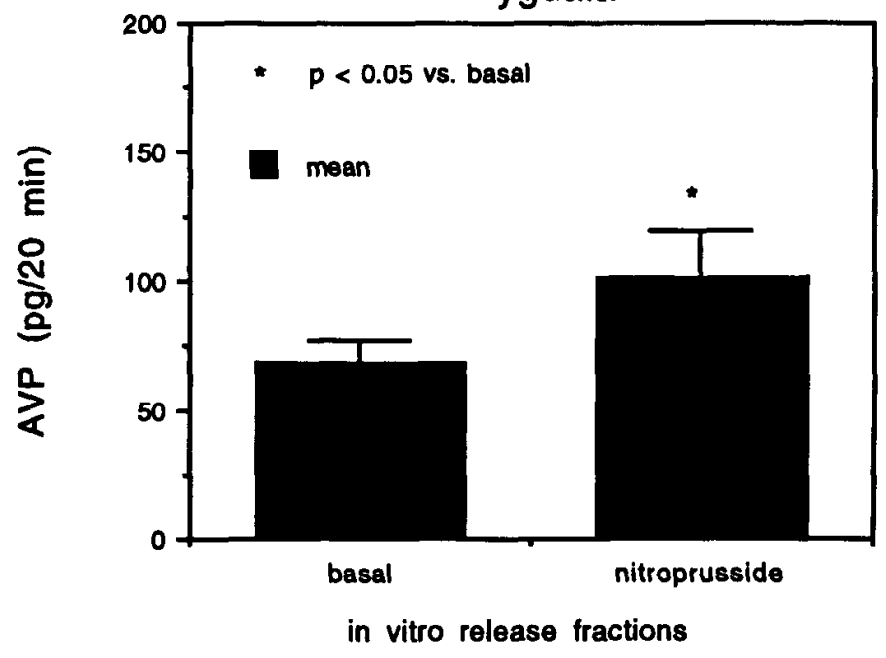

Figure 2. Effect of nitroprusside on the basal AVP release from the hypothalamus $(A)$ and amygdala $(B)$. After an $80 \mathrm{~min}$ preincubation, a baseline sample was collected for a period of $20 \mathrm{~min}$. Between 100 and $120 \mathrm{~min}$, incubation was carried out in the presence of nitroprusside $(100 \mu \mathrm{M})$. All values given are means \pm SEM. $n=20$ for hypothalamus $(A) ; n=8$ for amygdala $(B){ }^{*}, p<0.05$ versus basal.

increased the AVP release from both the hypothalamus and amygdala, respectively.

\section{Effect of LNMA and cobalt chloride on the IL-2-induced AVP release}

To determine whether IL-2 induces the AVP release via NO, the IL-2-induced AVP release was assessed in the presence of $10 \mu \mathrm{M}$ LNMA, an inhibitor of NOS. LNMA did not alter the basal AVP release from either the hypothalamus or amygdala (Fig. 3A,B). However, LNMA completely blocked the IL-2 (100 $\mathrm{U} / \mathrm{ml}$ )-induced AVP release from both brain regions. To study whether the IL-2-induced AVP release is calcium dependent, 
A

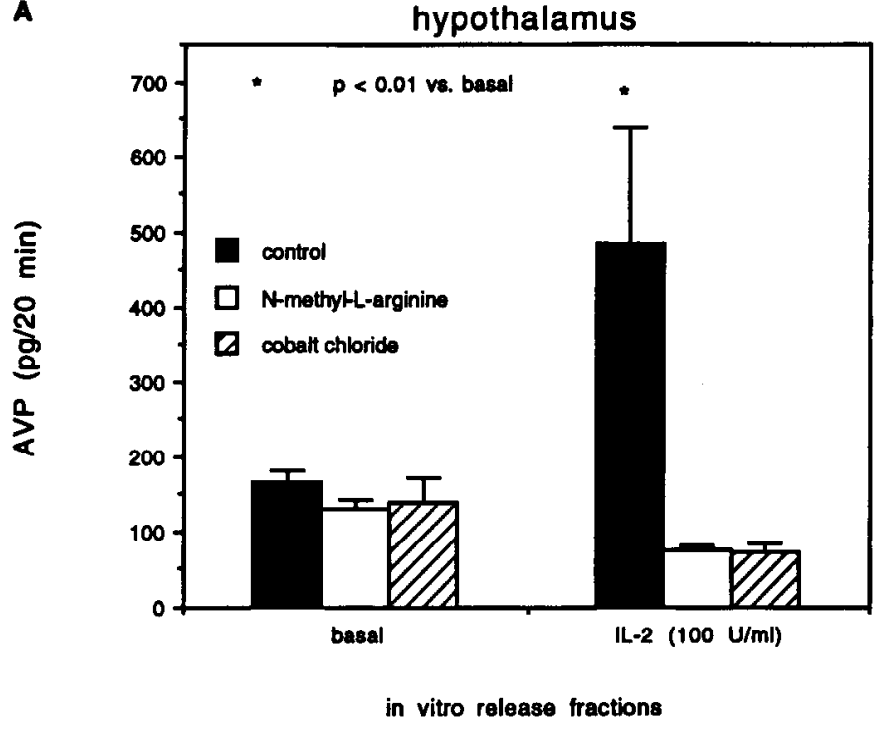

B

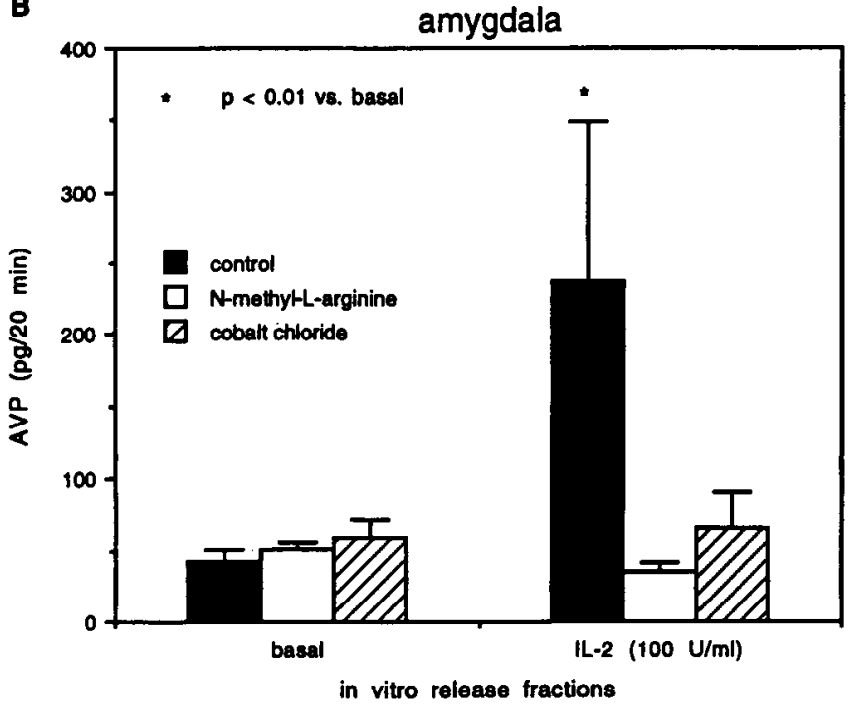

Figure 3. Effect of LNMA and cobalt chloride on the IL-2-induced AVP release from the hypothalamus $(A)$ and amygdala $(B)$. After an 80 min preincubation, samples were collected for a period of $80 \mathrm{~min}$. Between 80 and 120 min, incubation was carried out in the presence or absence of LNMA $(10 \mu \mathrm{M})$ or cobalt chloride $(10 \mathrm{mM})$. IL-2 (100 $\mathrm{U} / \mathrm{ml}$ ) was present between 100 and $120 \mathrm{~min}$. All values given are means \pm SEM. $n=7-19$ for hypothalamus $(A) ; n=14-28$ for amygdala $(B)$ $*, p<0.01$ versus basal.

hypothalamic and amygdala slices were stimulated by IL-2 (100 $\mathrm{U} / \mathrm{ml}$ ) in the presence of $10 \mathrm{mM} \mathrm{CoCl}_{2}$, a nonspecific blocker of calcium channels (Cooper et al., 1991). In the presence of $\mathrm{CoCl}_{2}$, the effects of IL-2 were completely antagonized; IL-2 no longer stimulated AVP release (Fig. $3 A, B$ ).

Effect of LNMA and DNMA on the acetylcholine-induced AVP release

Next we examined the role of NO in the AVP released by other neurotransmitters, such as acetylcholine and norepinephrine. Acetylcholine is known to evoke a significant increase in AVP release from the hypothalamus and the amygdala (Raber et al., 1994). To determine the role of NO in the acetylcholine-induced

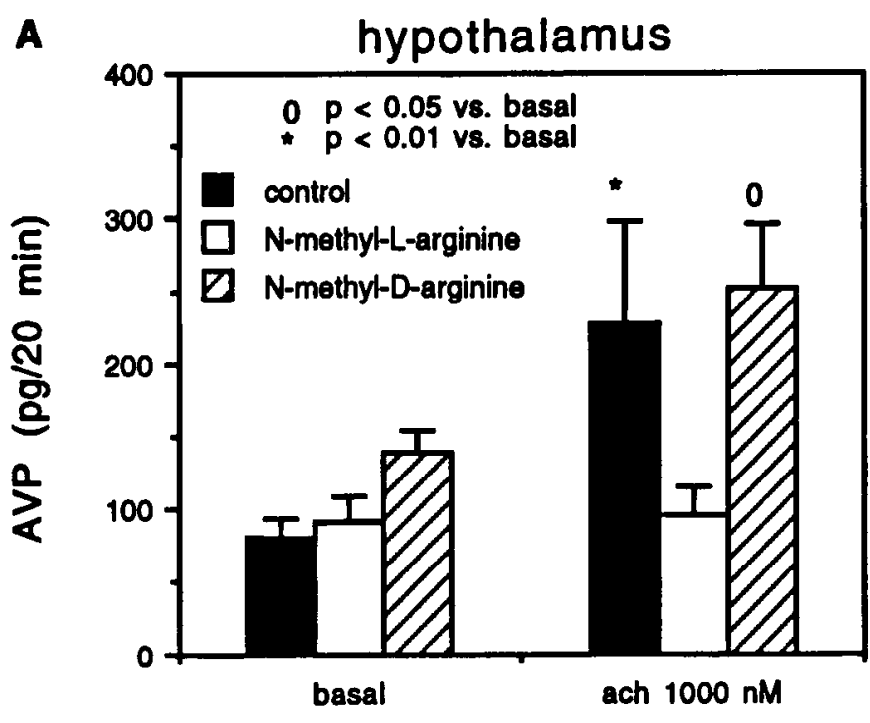

in vitro release fractions

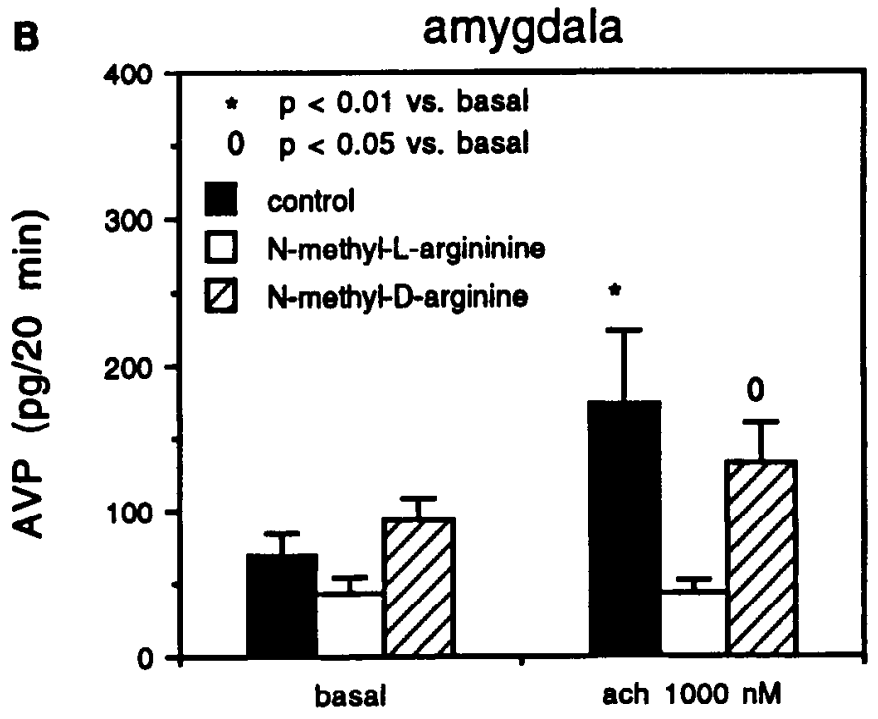

in vitro release fractions

Figure 4. Effect of LNMA and DNMA on the acetylcholine-induced AVP release from the hypothalamus $(A)$ and amygdala $(B)$. After an 80 min preincubation, samples were collected for a period of $80 \mathrm{~min}$. Between 80 and $120 \mathrm{~min}$, incubation was carried out in the absence or presence of LNMA or DNMA $(10 \mu \mathrm{M})$. Acetylcholine $(1 \mu \mathrm{M})$ was present during the subsequent period (between 100 and $120 \mathrm{~min}$ ). All values given are means \pm SEM. $n=7-13$ for hypothalamus $(A) ; n=9-10$ for amygdala $(B) .^{*}, p<0.01$ versus basal; $0, p<0.05$ versus basal.

AVP release, the $1 \mu \mathrm{M}$ acetylcholine-induced AVP release in the presence of $10 \mu \mathrm{M}$ LNMA was examined (Fig. $4 A, B$ ). LNMA completely blocked the acetylcholine-induced AVP release from the hypothalamus and amygdala. In order to ascertain that the inhibition of the acetylcholine-induced AVP release is specific, the acetylcholine-induced AVP release was assessed in the presence of $10 \mu \mathrm{M}$ DNMA, the inactive analog of LNMA. DNMA 
A

A. hypothalamus

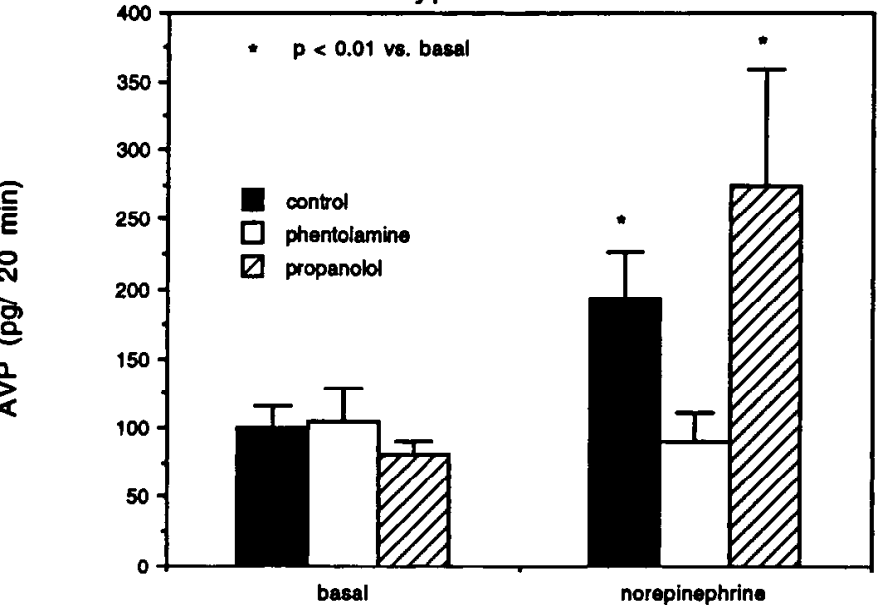

in vitro release fractions
A

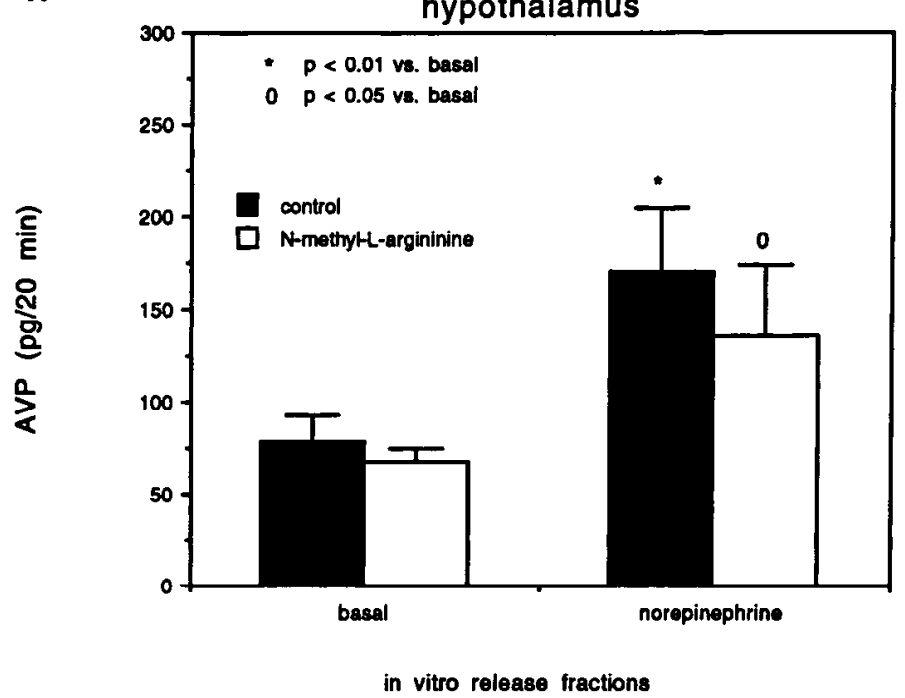

B

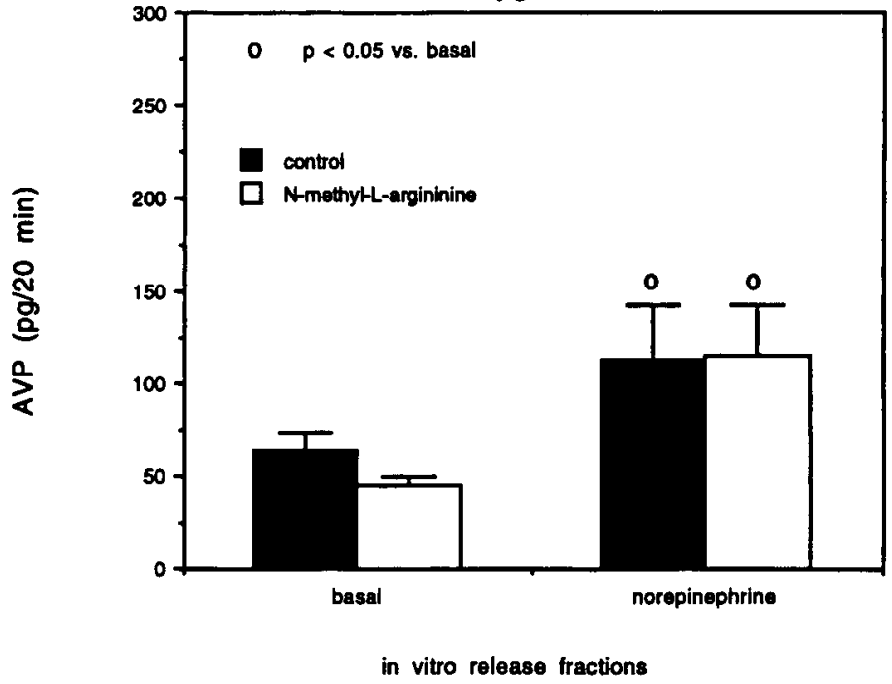

Figure 5. Involvement of $\alpha$-/but not $\beta$ - adrenergic receptors in the norepinephrine-induced AVP release from the hypothalamus $(A)$ and amygdala $(B)$. After an $80 \mathrm{~min}$ preincubation, samples were collected for a period of $80 \mathrm{~min}$. Between 80 and $120 \mathrm{~min}$, incubation was carried out in the absence or presence of propanolol $(10 \mu \mathrm{M})$ or phentolamine $(10 \mu \mathrm{M})$. Norepinephrine $(1 \mu \mathrm{M})$ was present during the subsequent period (between 100 and $120 \mathrm{~min}$ ). All values given are means \pm SEM. $n=8-13$ for hypothalamus $(A) ; n=9-21$ for amygdala $(B) .{ }^{*}, p<0.01$ versus basal; $0, p<0.05$ versus basal.

did not significantly alter the acetylcholine-induced AVP release in both brain regions.

\section{Effect of phentolamine and propanolol on the norepinephrine-induced AVP release}

Norepinephrine $(1 \mu \mathrm{M})$ strongly induced the release of AVP not only from the hypothalamus but also from the amygdala (Fig. $5 A, B)$. To investigate the adrenergic receptor(s) involved in the AVP release from these brain regions, the norepinephrine-induced AVP release in the presence of phentolamine or propanolol was assessed. Propanolol $(10 \mu \mathrm{M})$ did not significantly alter the norepinephrine-induced AVP release from either the hypothalamus or the amygdala. However, phentolamine $(10 \mu \mathrm{M})$
Figure 6. Effect of LNMA on the norepinephrine-induced AVP release from the hypothalamus $(A)$ and amygdala $(B)$. After an 80 min preincubation, samples were collected for a period of $80 \mathrm{~min}$. Between 80 and $120 \mathrm{~min}$, incubation was carricd out in the absence or presence of LNMA $(10 \mu \mathrm{M})$. Norepinephrine $(1 \mu \mathrm{M})$ was present during the subsequent period (between 100 and $120 \mathrm{~min}$ ). All values given are means \pm SEM. $n=9-12$ for hypothalamus $(A) ; n=10-17$ for amygdala $(B)$. *, $p<0.01$ versus basal; $0, p<0.05$ versus basal.

completely blocked the norepinephrine-induced AVP release from these areas.

\section{Effect of LNMA on the norepinephrine-induced AVP release}

To study if NO mediated signaling is involved in the norepinephrine-induced AVP release from the hypothalamus or amygdala, the norepinephrine-evoked release was assessed in the presence of LNMA. As shown in Figure 6, $A$ and $B$, LNMA (10 $\mu \mathrm{M})$ did not significantly alter the norepinephrine-induced AVP release from the hypothalamus or the amygdala.

\section{Discussion}

Our results provide evidence for a rapid calcium- and dosedependent release of AVP by IL-2, not only from the rat hy- 
pothalamus, but also from the amygdala in vitro. In addition, sodium nitroprusside, a generator of NO, also induces AVP release. Further, our findings demonstrate that while the IL-2and acetylcholine-induced AVP release may be mediated via production of NO, the AVP release induced by norepinephrine is not. The norepinephrine-induced AVP release is antagonized by phentolamine but not by propanolol, suggesting an $\alpha$-adrenergic receptor-mediated AVP response in both the hypothalamus and the amygdala.

The IL-2-induced release of AVP from the amygdala also raises the possible involvement of the amygdala in neuroimmune interactions. This is in agreement with the proposed role for the amygdala in the immune response, based on measurements of the cellular immune response as well as DNA synthesis after small electrolytic lesions (Masek et al., 1992). They suggest three possible immune-regulatory neurocircuits: (1) the catecholaminergic cell groups $A_{1}-\mathrm{A}_{7}$ in reticular formation, nucleus parabrachialis, and central nucleus of the amygdala; (2) the serotonergic raphe groups $\mathrm{B}_{6}$ and $\mathrm{B}_{8}$, the hypothalamus, and the basomedial nucleus of the amygdala; (3) the basomedial and central nuclei of the amygdala and the medial frontal cingulate cortex areas 1 and 2.

The present findings that nitroprusside induces AVP release and that the IL-2-/and acetylcholine-induced AVP release is blocked by LNMA from the hypothalamus as well the amygdala, strongly suggest that NO can mediate AVP release. These findings are in agreement with the recently reported dose-dependent increase in plasma AVP after intracerebroventricular injection in rats of $S$ - nitroso- $N$-acetylpenicillamine (SNAP), which spontaneously breaks down to form NO, or L-arginine, the precursor for NO synthesis (Ota et al., 1993); these effects might explain the inhibition of water diuresis after intracerebroventricular injection of L-arginine in hydrated goats (Eriksson et al., 1982).

Nitroprusside $(100 \mu \mathrm{M})$ produced only moderate, but significant, increases in AVP release from both the hypothalamus and amygdala (Fig. $2 A, B$ ). This is in line with the relatively large doses of SNAP and of $L$-arginine required to produce moderate increases in plasma AVP (Ota et al., 1993) and the relatively small induction of prostaglandin $\mathrm{E}_{2}\left(\mathrm{PGE}_{2}\right)$ by nitroprusside $(100 \mu \mathrm{M})$ from the hypothalamus in vitro (Rettori et al., 1992). The reason for this effect is not yet clear.

Two main classes of NOS can be distinguished, a calciumindependent calmodulin-containing endotoxin and/or cytokineinducible form of the enzyme and a calcium-dependent constitutive form (for review, see Henry et al., 1993). The blocking of the IL-2-induced AVP release from both the hypothalamus and the amygdala by cobalt chloride (Fig. $3,4, B$ ) may indicate the involvement of the constitutive form of NOS or the inability of the activated enzyme to release AVP in the absence of calcium and a potential direct effect of $\mathrm{CoCl}_{2}$ on AVP release from secretory granules. However, the observed effects induced by IL2 , acetylcholine, and nitroprusside occurred within $20 \mathrm{~min}$, while the cytokine induction of NOS shows a several hour delay (Kilbourn and Belloni, 1990; Moncada et al., 1991; Simmons and Murphy, 1993). These time differences support the involvement of the constitutive enzyme. The basal AVP release from both the hypothalamus, as well as the amygdala, is unaffected by NMLA or cobalt chloride (Fig. $3 A, B$ ). This indicates that NO is unlikely to mediate basal AVP release.

The present findings that IL-2- and acetylcholine-induced AVP release are mediated via production of NO, but not that induced by norepinephrine, are similar to in vitro data for CRF. In that case IL-2 stimulated hypothalamic CRF release in some hands (Calogero et al., 1987; Cambronero et al., 1992), but not others (Buzetti et al., 1988; Navarra et al., 1991). In addition NO signaling has been implicated in the IL-2 or cholinergic induction of hypothalamic CRF release, but not that induced by norepinephrine (Karanth et al., 1993). Our observation that AVP was clearly released from the hypothalamus by IL-2 suggests that in addition to CRF, AVP may also mediate the IL-2 stimulation of ACTH secretion (Bindon et al., 1983; Lotze et al., 1985; Atkins et al., 1986; Denicoff et al., 1989).

The mechanism for the IL-2 modulation of AVP release is still to be determined. It is unlikely that IL-2, at our doses tested $(1-100 \mathrm{U} / \mathrm{ml})$, interacted with acetylcholine to cause the AVP release. IL-2 does not change the basal acetylcholine release and decreases the potassium-evoked acetylcholine release from either hippocampal or frontal cortical slices (Araujo et al., 1989; Hanisch et al., 1993); IL-2 only increases the evoked release of acetylcholine in the hippocampus at very low concentrations $(1.5 \mathrm{mU} / \mathrm{ml})$ (Hanisch et al., 1993).

The nature of the IL-2 receptor signal transduction also remains unclear. The IL-2 receptor components $(\alpha, \beta$, and $\gamma)$ lack an intrinsic protein kinase domain, common to other growth factor receptors, and may utilize Src family tyrosine kinases and/or $\mathrm{p} 21^{\text {ras }}$ for the induced phosphorylation of cellular proteins (for review, see Taniguchi and Minami, 1993). Hypothetically, the activated IL-2 receptor could phosphorylate cholinergic receptors and in this way induce AVP release. For purified rat brain muscarinic receptors, carbachol-induced phosphorylation has been reported, and their phosphorylation states correlate with translocation and recycling of these receptors between plasma membrane and cytosol (Ho et al., 1990). However, the biological function of this phosphorylation is not yet clear. Some reports suggest that IL-2 stimulates T-cell proliferation by decreasing cAMP production and PKC activation (Farrar and Anderson, 1985; Evans et al., 1987; Altman et al., 1992). Interestingly, $\mathrm{PKC}$ activation increased the electrically evoked neurohypophysial AVP release in vitro, while PKC inhibition reduced it (Racke et al., 1989), raising an alternative possibility for the mechanism of IL-2-induced AVP release.

For some analogs of $\mathrm{L}$-arginine, direct effects on muscarinic receptors have been reported (Buxton et al., 1993). The fact that $N^{8}$-nitro-L-arginine (L-NAME), but not LNMA, seems to be a competitive muscarinic receptor antagonist indicates that the observed inhibition of the acetylcholine-induced AVP release occurs by blocking NO production. NO was reported to be involved in the induction of cGMP production by muscarinic receptors in rat primary cortical cultures, containing glial and neuronal elements (Castoldi et al., 1993). Thus, blocking NO synthesis may prevent muscarinic signal transduction. This could explain the inhibition of acetylcholine-induced AVP release in the presence of LNMA (Fig. $4 A, B$ ), since a blockade of the muscarinic receptor alone is sufficient to antagonize completely the acetylcholine-induced AVP release in the hypothalamus and amygdala (Raber et al., 1994).

The potent effect of IL-2 on the release of AVP could be due to a direct effect on AVP neurons or via an effect on astrocytes and/or microglia. The recently reported dose-dependent induction by purified rat IL-2 of L- arginine-dependent cGMP levels and protein synthesis in astrocytes (Simmons and Murphy, 1993) and the presence of AVP receptors on these cells (Hosli et al., 1992) raise the possibility of astrocytic involvement in the interaction between IL-2 and AVP. 
The noradrenergic system controlling hypothalamic AVP release is localized mainly in the PVN and SON, and to a small extent in the dorsomedial nucleus (Leibowitz et al., 1990). The PVN and SON are innervated by noradrenergic fibers from the $A_{1}$ - and $A_{2}$-catecholaminergic cells of the brainstem and from the locus coeruleus (McNeil and Sladek, 1980; Sawchenko and Swanson, 1982) and the presence of $\alpha 1, \alpha 2$, and $\beta$ adrenergic receptors in the PVN and SON have been reported (Leibowitz et al., 1982; Unnerstall et al., 1984). In the present study, we demonstrate that the norepinephrine-induced AVP release is antagonized by phentolamine but not by propanolol, suggesting an $\alpha$-adrenergic receptor-mediated AVP response in both the hypothalamus, as well as the amygdala. These results are in agreement with other reports showing a norepinephrine-mediated stimulatory effect on the hypothalamic AVP release (Benetos et al., 1986; Leibowitz et al., 1990; Renaud and Bourque, 1991), which is mediated by $\alpha$ adrenoceptors (Hillhouse and Milton, 1989; Veltmar et al., 1992).

Norepinephrine can also induce AVP release from the amygdala. Among the AVP-containing neurons identified in the amygdala (De Vries et al., 1985), the central amygdaloid nucleus may be a possible site of interaction between norepinephrine and AVP, like described for its interaction with CRF (Ray et al., 1993), since in the late phase of hypertension there is an increased release of norepinephrine detected, using push-pull techniques (Dietl, 1987). The amygdaloid complex is involved in stress-related reactions (Singh et al., 1990) and in the regulation of the hypothalamo-pituitary-adrenal (HPA) axis (Dunn and Whitener, 1986). The involvement and requirement for central catecholamines in the HPA response to exogenous cytokines (Weidenfeld et al., 1989) or stress (Gaillet et al., 1991), for adrenergic receptors in the PVN in the angiotensin II-induced AVP release (Veltmar et al., 1992), and the nicotineinduced neuronal activation in brainstem catecholaminergic regions and their projection fields in parvocellular PVN and SON (Matta, 1993), suggest a significant role in regulating AVP release.

In summary, we have found that IL-2 can modulate the AVP release from the hypothalamus and amygdala in vitro, suggesting a role for not only the hypothalamus, but also the amygdala in neuroimmune interactions. In addition, NO was found to be involved in the IL-2- and acetylcholine-induced AVP release from both brain regions, but not in the one induced by $\alpha$ - adrenoceptor stimulation. The exact mechanism by which IL-2 modulates AVP release remains to be determined, and could clarify pathophysiologic or toxic effects of high brain levels of IL-2.

\section{References}

Altman A, Mally MI, Isakov N (1992) Phorbol ester synergizes with $\mathrm{Ca}^{2+}$ ionophore in activation of protein kinase $\mathrm{C}(\mathrm{PKC}) \alpha$ and PKC $\beta$ isozymes in human $T$ cells and in induction of related cellular functions. Immunology 76:465-471.

Araujo D, Lapchak PA, Collier B, Quirion R (1989) Localization of interleukin-2 immunoreactivity and interleukin-2 receptors in the rat brain: interaction with the cholinergic system. Brain Res 498:257266.

Atkins M, Gould JA, Allegreta M, Li JJ, Dempsey RA, Rudders RA, Parkinson DR, Reichlin S, Mier JW (1986) Phase I evaluation of recombinant interleukin-2 in patients with advanced malignant disease. J Clin Oncol 4:1380-1391.

Benetos A, Gavras 1, Gavras H (1986) Norepinephrine applied in the paraventricular hypothalamic nucleus stimulates vasopressin release. Brain Res 381:322-326 [erratum in Brain Res 400:412, 1987].
Benveniste E, Herman PK, Whitaker JN (1987) Myelin basic proteinspecific RNA levels in interleukin-2-stimulated oligodendrocytes. J Neurochem 49:1274-1279.

Berkenbosch F, van Oers J, Del Rey A, Tilders F, Besedovsky H (1987) Cortocotropin-releasing factor-producing neurons in the rat activated by interleukin-1. Science 238:524-526.

Berkenbosch F, de Goeij DEC, Del Rey A, Besedovsky HO (1989) Neuroendocrine, sympathetic and metabolic responses induced by interleukin-1. Neuroendocrinology 50:570-576.

Bindon C, Czerniecki M, Ruell P, Edwards A, McCarthy WH, Harris $R$, Hersey $P$ (1983) Clearance rates and systemic effects of intravenously administered interleukin-2 containing preparation in human subjects. Br J Cancer 47:123-134.

Bindoni M, Perciavalle V, Beretta S, Belluardo N, Diamantstein T (1988) Interleukin 2 modifies the bioelectric activity of some neurosecretory nuclei in the rat hypothalamus. Brain Res 462:10-14.

Bredt D, Snyder SH (1992) Nitric oxide, a novel neuronal messenger. Neuron 8:3-11.

Buxton I, Cheek DJ, Eckman D, Westfall DP, Sanders KM, Keef KD (1993) $N^{\mathrm{a}}$-nitro L-arginine methyl esters and other alkyl esters of arginine are muscarinic antagonists. Circ Res 72:387-395.

Buzetti R, Tsagarakis S, Lavender P, Rees LH, Besser GM, Grossman A (1988) Effects of cytokines and epidermal growth on CRF-41 release from rat hypothalamus in vitro. J Endocrinol [Suppl] 119:95.

Calogero A, Luger T, Gallucci WT, Gold PW, Chrousos GP (1987) Interleukin 1 and interleukin 2 stimulate hypothalamic corticotropin releasing hormone but not ACTH secretion in vitro. In: Proceedings of the 69th annual meeting of the Endocrine Society, Indianapolis, IN, p 271.

Calogero A, Bernardini R, Marglois AN, Bagdy G, Galucci WT, Munson PJ, Tamarkin L, Tomai TP, Brady L, Gold PW, Chrousos GP (1989) Effects of serotonergic agonists and antagonists on corticotropin releasing hormone secretion by explanted rat hypothalami. Peptides 10: 189-200.

Cambronero J, Rivas FJ, Borell J, Guaza C (1992) Interleukin-2 induces corticotropin-releasing hormone release from superfused rat hypothalami: influence of glucocorticoids. Endocrinology 131:677683.

Castoldi A, Manzo L, Costa LG (1993) Cyclic cGMP formation induced by muscarinic receptors is mediated by nitric oxide synthesis in rat cortical primary cultures. Brain Res 610:57-61.

Claman H (1987) The biology of the immune response. JAMA 258 : 2834-2840

Cohen J, Arai M, Prak EL, Brooks SA, Young LH, Prystowsky MB (1992) Characterization of a novel mRNA expressed by neurons in mature brain. J Neurosci Res 31:273-284.

Cooper J, Bloom FE, Roth RH (1991) The biochemical basis of neuropharmacology, pp 28-29. New York: Oxford UP.

Croiset G, Heijnen CJ, de Wied D (1990) Passive avoidance behavior, vasopressin and the immune system. Neuroendocrinology 51:156161.

De Vries GJ, Buijs RM, Van Leeuwen FW, Caffe AR, Swaab DF (1985) The vasopressinergic innervation of the brain in normal and castrated rats. J Comp Neurol 233:236-254.

Denicoff K, Durkin TM, Lotze MT, Quinlan PE, Davis CL, Listwak SJ, Rosenberg SA, Rubinow DR (1989) The neuroendocrine effects of interleukin-2 treatment. J Clin Endocr Metab 69:402-410.

Dietl H (1987) Differential effects of experimentally induced blood pressure changes on the release of catecholamines in hypothalamic and limbic areas of rats. Life Sci 41:217-226.

Dunn JD, Whitener J (1986) Plasma corticosterone responses to electrical stimulation of the amygdaloid complex: cytoarchitectural specificity. Neuroendocrinology 42:211-217.

Ellison M, Povlishock JT, Merchant RE (1987) Blood-brain barrier dysfunction in cats following recombinant interleukin-2 infusion. Cancer Res 47:5765-5770.

Eriksson S, Appelgren B, Rundgren M, Andersson B (1982) Vasopressin release in response to intracerebroventricular L-alanine and L-arginine, and its dependence upon $\mathrm{CSF} \mathrm{NaCl}$ concentration. Acta Physiol Scand 116:75-81.

Evans S, Beckner SK, Farrar WL (1987) Stimulation of specific GTP binding and hydrolysis activities in lymphocyte membrane by interleukin-2. Nature 325:166-168.

Farrar W, Anderson WB (1985) Interleukin 2 stimulates association of protein kinase $C$ with plasma membrane. Nature 315:233-235. 
Gaillet S, Lachuer J, Malaval F, Assenmacher I, Szafarczyk A (1991) The involvement of noradrenergic ascending pathways in the stressinduced activation of ACTH and corticosterone secretion is dependent on the nature of stressors. Exp Brain Res 87:173-180.

Garthwaite J (1991) Glutamate, nitric oxide and cell-cell signalling in the nervous system. Trens Neurosci 14:60-67.

Hanish U-K, Seto D, Quirion R (1993) Modulation of hippocampal acetylcholine release: a potent central action of interleukin-2. J Neurosci 13:3368-3374.

Henry Y, Lepoivre M, Drapier J-C, Ducrocq C, Boucher J-L, Guissani A (1993) EPR characterization of molecular targets for NO in mammalian cells and organelles. FASEB J 7:1124-1134.

Hillhouse E, Milton NGN (1989) Effect of noradrenaline and $\gamma$-aminobutyric acid on the secretion of corticotropin-releasing factor- 41 and arginine vasopressin from the rat hypothalamus in vitro. J Endocrinol 122:719-723.

Ho AK, Zhang YJ, Duffield R, Zheng GM (1990) Phosphorylationdephosphorylation of muscarinic acetylcholine receptors: evidence for the in vivo and in vitro release of receptors from brain plasma membrane. Cell Signal 2:451-460.

Hosli E, Lefkovits M, Kaser H, Hosli L (1992) Evidence for receptors for arginine vasopressin, atrial natriuretic peptide and bradykinin on cultured astrocytres. In: Proceedings of the 15th annual meeting of European Neuroscience Association, 5:32.

Johnson HM, Torres BA (1985) Regulation of lymphokine production by arginine vasopressin and oxytocin: modulation of lymphocyte function by neurohypophyseal hormones. J Immunol 135:773s-775s.

Jones C, Pickering BT (1969) Comparison of the effects of water deprivation and sodium chloride inhibition on the hormone content of the neurohypophysis of the rat. J Physiol (Lond) 203:449-458.

Karanth S, Lyson K, McCann SM (1993) Role of nitric oxide in interleukin-2-induced corticotropin-releasing factor release from incubated hypothalami. Proc Natl Acad Sci USA 90:3383-3387.

Kilbourn R, Belloni P (1990) Endothelial cell production of nitrogen oxide in response to interferon- $\gamma$ in combination with tumor necrosis factor, interleukin-1 or endotoxin. J Natl Canc Inst 82:772-776.

Lapchak P, Araujo DM (1993) Hippocampal IL-1, IL-2, and IL-3, but not IL-6 levels are elevated in Alzheimer's but not Parkinson's disease. In: Proceedings of the annual meeting for Neuroscience, $p$ 191.

Lapchak P, Araujo DM, Quirion R, Beaudet A (1991) Immunoautoradiographic localization of interleukin 2-like immunoreactivity and interleukin 2 receptors (Tac antigen-like immunoreactivity) in the rat brain. Neuroscience 44:173-184.

Leibowitz S, Jhawar-Uniyal M, Dvorkin B, Malkman NH (1982) Distribution of $\alpha$-adrenergic, $\beta$-adrenergic and dopaminergic receptors in discrete hypothalamic areas in rat. Brain Res 233:92-114.

Leibowitz S, Eidelman D, Suh JS, Diaz S, Sladek CD (1990) Mapping study of noradrenergic stimulation of vasopressin release. Exp Neurol 110:298-305

Licinio J, Seibyl JP, Altemus M, Charney DS, Krystal JH (1993) Elevated CSF levels of interleukin-2 in neuroleptic-free schizophrenic patients. Am J Psychiatry 150:1408-1410.

Lotze M, Frana LW, Sharow SO, Robb RJ, Rosenberg SA (1985) In vivo administration of purified interleukin 2 . Half life and immunological effects on the Jurkat cell line derived interleukin-2. J Immunol 134:157-166.

Luber-Narod J, Rogers J (1988) Immune system associated antigens expressed by cells of the human central nervous system. Neurosci Lett 94:17-22.

Madison D (1993) Pass the nitric oxide. Proc Natl Acad Sci USA 90: 4329-4331.

Masek K, Petrovicky P, Seifert J (1992) An introduction to the possible role of central nervous system structures in neuroendocrine-immune interaction. Int J Immunopharmacol 14:317-322.

Matta SG, Foster CA, Sharp BM (1993) Nicotine stimulates the expression of cFos protein in the parvocellular paraventricular nucleus and brainstem catecholaminergic regions. Endocrinology 132:21492156.

McNeil T, Sladek JR Jr (1980) Simultaneous monoamine histofluorescence and neuropeptide immunohistochemistry. II. Correlative distribution of catecholamine varicosities and magnocellular neurosecretory neurons in the rat supraoptic and paraventricular nuclei. J Comp Neurol 193:1023-1033.

Moffett C, Paden CM (1993) Nitric oxide synthase is present in both oxytocin and vasopressin neurons. In: Proceedings of the annual meeting for Neuroscience, $p 93$.

Moncada S, Palmer RMJ, Higgs EA (1991) Nitric oxide: physiology, pathophysiology, and pharmacology. Pharmacol Rev 43:109-142.

Navarra P, Tsagarakis S, Faria MS, Rees LH, Besser GM, Grossman AB (1991) Interleukins-1 and-6 stimulate the release of corticotropin-releasing hormone-41 from rat hypothalamus in vitro via the eicasanoid cyclooxygenase pathway. Endocrinology 128:37-44.

Nicto-Sampredo M, Chandy KG (1987) Interleukin-2 like activity in injured brain. Neurochem Res 12:723-727.

Nistico G, De Sarro G (1991) Is interleukin 2 a neuromodulator in the brain? Trends Neurosci 14:146-150.

Ota E, Crofton JT, Festavan GT, Share L (1993) Evidence that nitric oxide can act centrally to stimulate vasopressin release. Neuroendocrinology 57:955-959.

Pardy K, Murphy D, Carter D, Hui KM (1993) The influence of interleukin-2 on vasopressin and oxytocin gene expression in the rodent hypothalamus. J Neuroimmunol 42:131-138.

Paxinos P, Watson C (1986) The rat brain in stereotaxic coordinates. Sydney: Academic.

Pow D (1992) NADPH-diaphorase (nitric oxide synthase) staining in the rat supraoptic nucleus is activity dependent: possible functional implications. J Neuroendocrinol 4:377-380.

Raber J, Merlo Pich E, Koob GF, Bloom FE (1994) IL- $1 \beta$ potentiates the acetylcholine induced release of vasopressin from the hypothalamus in vitro, but not from the amygdala. Neuroendocrinology 59: 208-217.

Racke K, Burns F, Haas B, Niebauer J, Pitzius E (1989) Frequencydependent effects of activation and inhibition of protein kinase $C$ on neurohypophysial release of oxytocin and vasopressin. Naunyn Schmiedebergs Arch Pharmacol 339:617-624.

Ray A, Henke PG, Gulati K, Sen P (1993) The amygdaloid complex, corticotropin releasing factor and stress-induced gastric ulcerogenesis in rats. Brain Res 624:286-290.

Renaud L, Bourque CW (1991) Neurophysiology and neuropharmacology of hypothalamic magnocellular neurons secreting vasopressin and oxytocin. Prog Neurobiol 36:131-169.

Rettori V, Gimeno M, Lyson K, McCann SM (1992) Nitric oxide mediates norepinephrine-induced prostaglandin $\mathrm{E}_{2}$ release from the hypothalamus. Proc Natl Acad Sci USA 89:11543-11546.

Rosenberg S, Lotze MT (1986) Cancer immunotherapy using interleukin-2 and interleukin-2-activated lymphocytes. Annu Rev Immunol 4:681-709.

Sabath D, Podolin PL, Comber PG, Prystowsky MB (1990) cDNA cloning and characterization of interleukin 2-induced genes in a cloned T helper lymphocyte. J Biol Chem 265:12671-12678.

Saphier D, Ovadia H (1990) Selective facilitation of putative corticotropin-releasing factor-secreting neurons by interleukin-1. Neurosci Lett 114:283-288.

Sapolsky R, Rivier C, Yamamoto G, Plotsky P, Vale W (1987) Interleukin-1 stimulates the secretion of hypothalamic corticotropinreleasing factor. Science 238:522-524.

Saris S, Rosenberg A, Friedman RB, Rubin JT, Barba D, Oldfield EH (1988) Penetration of recombinant interleukin-2 across the blood cerebrospinal fluid barrier. J Neurosurg 69:29-34.

Sawchenko P, Swanson LW (1982) The organization of noradrenergic pathways from the brainstem to the paraventricular and supraoptic nuclei in the rat. Brain Res Rev 4:275-325.

Sessa M, Nemni R, Innaccone S, Quattrini A, Confalonieri V, Canal N (1992) In vivo modulation of myelin gene expression by human recombinant IL-2. Brain Res Mol Brain Res 12:331-334.

Shimojo M, Imai Y, Najakima K, Mizushima S, Uemura A, Kohsaka S (1993) Interleukin-2 enhances the viability of primary cultured rat neocortical neurons. Neurosci Lett 151:170-173.

Simmons M, Murphy S (1993) Cytokines regulate L-arginine-dependent cyclic GMP production in rat glial cells. Eur J Neurosci 5:825831.

Singh VB, Onaivi ES, Phan TH, Boadlebiber MC (1990) The increases in rat cortical and midbrain tryptophan hydroxylase activity in response to acute or repeated sound stress are blocked by bilateral lesions to the central nucleus of the amygdala. Brain Res 530:49-53.

Skowsky W, Rosembloom AA, Fisher DA (1974) Radioimmunoassay of arginine vasopressin in serum: development and application. J Clin Endocrinol Metab 38:278-287.

Spinedi E, Hadid R, Daneva T, Gaillard RC (1992) Cytokines stim- 
ulate the CRH but not the vasopressin neuronal system; evidence for a median eminence site of interleukin- 6 action. Neuroendocrinology $56: 46-53$.

Swaab D, Nijveldt F, Pool CW (1975) Distribution of oxytocin and vasopressin in the rat supraoptic and paraventricular nucleus. J Endocrinol 67:461-462.

Taniguchi T, Minami Y (1993) The IL-2/IL-2 receptor system: a current overview. Cell 73:5-8.

Unnerstall J, Kopajtic TA, Kuhar M (1984) Distribution of $\alpha_{2}$ agonist binding sites in the rat and human central nervous system: analysis of some functional, anatomic correlates of the pharmacologic effects of clonidine and related adrenergic agents. Brain Res Rev 7:69-101.

Urba W, Steis RG, Longo DL, Kopp WC, Maluish AF, Marcon L, Nelson DL, Stevenson HC, Clark JW (1990) Immunomodulatory properties and toxicity of interleukin 2 in patients with cancer. Cancer Res 50:185-192.

Veltmar A, Culman J, Quadri F, Rascher W, Unger T (1992) Involvement of adrenergic and angiotensinergic receptors in the paraven- tricular nucleus in the angiotensin II-induced vasopressin release. J Pharmacol Exp Ther 263:1253-1260.

Villemain F, Girard JM, Owens T (1990) Immunohistochemical detection of interleukin-2 in normal mouse brain. In: Proceedings of the 20th annual meeting of The Society for Neuroscience, p 1213.

Watanobe H, Takebe K (1993) Intrahypothalamic perfusion with Interieukin- $1 \beta$ stimulates the local release of corticotropin-releasing hormone and arginine vasopressin and the plasma adrenocorticotropin in freely moving rats: a comparative perfusion of the paraventricular nucleus and the median eminence. Neuroendocrinology 57: 593-599.

Weidenfeld J, Abramsky O, Ovadia H (1989) Evidence for the involvement of the central adrenergic system in interleukin-1-induced adrenocorticol response. Neuropharmacology 28:1411-1414.

Weitzman R, Glatz TH, Fisher DA (1978) The effect of hemorrhage and hypertonic saline upon plasma oxytocin and arginine vasopressin in conscious dogs. Endocrinology 103:2154. 